\title{
PSYCHOPHYSIOLOGY
}

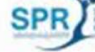

\section{Word onset phonetic properties and motor artefacts in speech production EEG recordings}

\begin{tabular}{|r|l|}
\hline Journal: & Psychophysiology \\
\hline Manuscript ID & PsyP-2017-0086.R1 \\
\hline Diley - Manuscript type: & Original article \\
\hline Complete List of Authors: & $\begin{array}{l}\text { Fargier, Raphaël; Universite de Geneve Faculte de Psychologie et des } \\
\text { Sciences de I'Education, } \\
\text { Bürki, Audrey; Universite de Geneve Faculte de Psychologie et des } \\
\text { Sciences de l'Education; Universitat Potsdam, Cognitive sciences, } \\
\text { department of linguistics } \\
\text { Pinet, Svetlana; Johns Hopkins School of Medicine, Department of } \\
\text { Neurology; Aix-Marseille Universite, CNRS, LPC } \\
\text { Alario, F.-Xavier; Aix-Marseille Universite, CNRS, LPC } \\
\text { Laganaro, Marina; Universite de Geneve Faculte de Psychologie et des } \\
\text { Sciences de I'Education }\end{array}$ \\
\hline Keywords: & $\begin{array}{l}\text { speech production, EEG < Methods, motor artefact, phonetics, picture } \\
\text { naming }\end{array}$ \\
\hline
\end{tabular}

SCHOLARONE

Manuscripts 


\title{
Word onset phonetic properties and motor artefacts in speech production EEG recordings
}

\author{
Raphaël Fargier ${ }^{1}$, Audrey Bürki ${ }^{1,2}$, Svetlana Pinet ${ }^{3,4}$, F.-Xavier Alario $^{4}$, Marina Laganaro ${ }^{1}$
}

1. FPSE, University of Geneva, Switzerland

2. Cognitive Sciences, Department of Linguistics, University of Potsdam, Karl-Liebknecht-Straße 24-25, 14476 Potsdam, Germany

3. Department of Neurology, School of Medicine, Johns Hopkins University, Baltimore, MD, USA

4. Aix Marseille Univ, CNRS, LPC, Marseille, France

Running head: Phonetic properties in speech production EEGs

\section{Corresponding author:}

Raphaël Fargier

42, boulevard du Pont d'Arve

1211 Genève

Switzerland

raphael.fargier@unige.ch

Phone number: (022 37) 98323 


\begin{abstract}
Electrophysiological research using verbal response paradigms faces the problem of muscle artefacts that occur during speech production or in the period preceding articulation. In this context, this paper has two related aims. The first is to show how the nature of the first phoneme influences the alignment of the event-related potentials (ERPs). The second is to characterize further the electroencephalographic (EEG) signal around the onset of articulation, both in temporal and frequency domains. Participants were asked to name out-loud pictures of common objects. We applied microstate analyses and time-frequency transformations of ERPs locked to vocal onset to compare the EEG signal between voiced and unvoiced labial plosive word onset consonants. We found a delay of about 40 milliseconds in the set of stable topographic patterns for $/ \mathrm{b} /$ relative to $/ \mathrm{p} /$ onset words. A similar shift was observed in the power increase of gamma oscillations $(30-50 \mathrm{~Hz})$, which had an earlier onset for $/ \mathrm{p} /$ trials ( $150 \mathrm{~ms}$ before vocal onset). This $40 \mathrm{~ms}$ shift is consistent with the length of the voiced proportion of the acoustic signal prior to the release of the closure in the vocal responses. These results demonstrate that phonetic features are an important parameter affecting response-locked ERPs and hence that the onset of the acoustic energy may not be an optimal trigger for synchronizing the EEG activity to the response in vocal paradigms. The indexes explored in this study provide a step forward in the characterization of muscle related artefacts in electrophysiological studies of speech and language production.
\end{abstract}

Key words: speech production, EEG, motor artefact, phonetics, picture naming 


\section{Introduction}

Neurophysiological activity with high temporal resolution (electroencephalography, or EEG, and magnetoencephalography, or $\mathrm{MEG}$ ) offer a unique window into the time course of cognitive processes. They have become a privileged tool to investigate the human mind in many fields of cognitive psychology. For example, research on speech and language production processes has seen a substantial increase in the use of EEG and MEG in the last decade (e.g., Ganushchak, Christoffels, \& Schiller, 2011; Indefrey, 2011; Munding, Dubarry, \& Alario, 2015; for reviews). The large majority of studies on language production used picture naming tasks, and examined the ERPs aligned on picture onset (e.g., Blackford, Holcomb, Grainger, \& Kuperberg, 2012; Strijkers, Costa, \& Thierry, 2010; Dell'acqua et al., 2010; Llorens, Trébuchon, Riès, Liégeois-Chauvel, \& Alario, 2014). Stimulus-aligned ERPs are particularly well suited to investigate the processes that occur shortly after the presentation of the stimulus. Consequently, early encoding processes (i.e., recognition of the picture, access to the concept or corresponding semantic representation) have received much more attention than encoding processes thought to occur later and closer to articulation (i.e., phonological or phonetic encoding processes in the sequential model of word production, Indefrey \& Levelt, 2004; Levelt, Roelofs, \& Meyer, 1999). Because the time interval between the onset of the stimulus and the onset of the vocal response is relatively long and varies greatly from participant to participant and from trial to trial, stimulus-aligned ERPs are much less suited to investigate the processes that occur closer to the articulation (see Riès, Janssen, Burle, \& Alario, 2013, for this rationale). Indeed, the choice of the time window of analysis is constrained by the faster responses in the dataset but, for many trials, the late processes have likely not yet taken place in this time window. Moreover, the variability of cognitive processes across trials presumably increases with the distance from the alignment point, compromising the detection of the effects of an experimental manipulation (Jung et al., 1999; Dubarry et al., in press).

The alignment of ERPs on the vocal response has proven extremely useful to target later stages of word production in many recent studies (Bürki, Pellet-Cheneval, \& Laganaro, 2015; Bürki, Sadat, Dubarry, \& Alario, 2016; Fargier \& Laganaro, 2016; Ganushchak \& Schiller, 2008; Laganaro, 2014; Laganaro \& Perret, 2011; Masaki, Tanaka, Takasawa, \& Yamazaki, 2001; Riès, Janssen, Dufau, Alario, $\&$ Burle, 2011). Such procedure raises, however, two methodological issues. The first concerns the point of alignment of the ERPs. Ideally, one would like to align the ERPs on the onset of the articulatory movement. In practice, this onset is estimated using the onset of energy in the acoustic signal. How exactly this onset relates to the onset of the articulatory movement depends on the properties of the phonemes. Rastle, Croot, Harrington, and Coltheart (2005) reported for instance that the time lag between the onset of motor execution and the onset of acoustic energy varies 
across phonemes (e.g., longer lags for stops than for consonants with other manner of articulation; longer lags for voiced than for voiceless). Consequently, if the linguistic material is not fully balanced in the first (and possibly also the second) phoneme, the time-locking of the ERPs will be jittered.

The second issue is the potential contamination of the neural signal by muscular artefacts. Although primarily designed to record cortical brain activity, EEG and MEG recordings also capture electrical activities originating from moto-neurons involved in articulation. Muscular activity incidental to speech production (such as pre-phonatory breath) is also associated with cortical potentials recorded by EEG and MEG that might be indiscernible from the cortical activity generated by the cognitive processes of interest (Deecke, Engel, Lang, \& Kornhuber, 1986; Tremoureux et al., 2014; Yoshida et al., 1999). In addition, research using vocal response paradigms faces the problem of concomitant muscular activity (e.g. face muscles for jaw movements, glosso-kinetic artefacts from tongue movements) during speech production or in the period preceding articulation (e.g. De Vos et al., 2010; Ganushchak \& Schiller, 2008; Goncharova et al., 2003; Ouyang et al., 2016; Porcaro, Medaglia, \& Krott, 2015; van der Linden et al., 2014; Whitham et al., 2007). This electromyographic activity is known to contaminate the EEG signal of interest. Speech production studies usually deal with artefacts by either avoiding to analyze the signal too close to the articulation (Strijkers, Costa, \& Thierry, 2010) or without articulation (see van Turennout, Hagoort, \& Brown, 1999; see also Schmitt et al, 2000) or by correcting the signal (James \& Hesse, 2005; Pham, Fine, \& Semrud-Clikeman, 2011; Urigüen \& Garcia-Zapirain, 2015; Vigario \& Oja, 2008). These later studies take advantage of different methods such as regression (Pham, Fine, \& Semrud-Clikeman, 2011) or blind source separation techniques (James \& Hesse, 2005) but they yielded contradictory results both for the frequency range and the extent of the period contaminated by articulation. To choose and apply these signal processing options efficiently in the future, a detailed understanding of the time window showing artefact-related activities and of their properties is required.

The purpose of the present study is to contribute to documenting these two methodological issues in the analysis of ERPs aligned to the vocal response, with two specific goals. Our first goal is to demonstrate how the nature of the first phoneme influences the point of alignment of the ERPs. This aim is achieved by comparing ERPs obtained in a picture naming task for words starting either with $/ \mathrm{p} /$ or $/ \mathrm{b} /$, that is two phonemes differing in voicing (i.e. vibration of vocal cords) but with similar movements of the other articulators. We hypothesize that the ERPs for $p$-initial and b-initial words will show similar waveforms but will differ in how they are distributed in time with a delay for $\mathrm{p}$ initial words as compared to b-initial words. To test this hypothesis, we rely on microstate analysis. These analyses are particularly appropriate to detect a temporal delay between two otherwise similar waveforms when these waveforms do not have clear ERP components (e.g. response-aligned 
ERPs; see results section). Our second aim is to characterize further the EEG signal around the onset of articulation, for voiced and unvoiced phonemes. While the presence of "artefacts" is widely acknowledged, much remains to be uncovered about how artefact-related activities impact the signal recorded at the scalp level (i.e., the signature of these artefacts) and on the time window during which these artefacts may occur (see Figure 5 in van der Linder et al., 2012). To address this issue, we chose to characterize the time-frequency profile of the scalp recordings for $/ \mathrm{p} / \mathrm{and} / \mathrm{b} /$ word onsets.

\section{Methods}

Subjects

18 right-handed and French speaking individuals participated in the study. None reported history of neurological disease.

\section{Material}

The stimuli were 20 black and white pictures from a French database (Alario \& Ferrand, 1999) and their respective names, to be presented 40 times each in a standard picture naming protocol.

Procedure

Participants sat in a sound-proof dimly lit room approximately $70 \mathrm{~cm}$ in front of a PC screen. The presentation of the trials was controlled by the software E-Prime (E-Studio, V2.0 Standard edition).

A trial started with a fixation cross presented for $500 \mathrm{~ms}$, then appeared a picture $(245 \times 240 \mathrm{px}$ on a grey screen) which remained on the screen between 1500 and 2000 ms. A blank white screen lasting $4000 \mathrm{~ms}$ was displayed every 4 trials to allow eye blinking. Participants were asked to produce the word corresponding to the picture as fast and accurately as possible. Each stimulus was presented 40 times in a pseudo-random order.

EEG acquisition

The EEG signal was recorded continuously using the Active-Two Biosemi EEG system (Biosemi V.O.F. Amsterdam, Netherlands) from 128 channels covering the entire scalp. Signals were sampled at 512 $\mathrm{Hz}$ (filters: DC to $104 \mathrm{~Hz}, 3 \mathrm{~dB} /$ octave slope). The custom online reference of the system is the common mode sense - driven right leg (CMS-DRL). Offline, ERPs were band-pass filtered to $0.2-50 \mathrm{~Hz}$ $\left(2^{\text {nd }}\right.$ order acausal Butterworth filter with-12 dB/octave roll-off) with a notch filter $(50 \mathrm{~Hz})$ and recalculated against the average reference. 


\section{Pre-processing and analyses}

\section{Selection of material for analysis}

As stated in the introduction, our aim was to analyse and contrast voiced vs. unvoiced consonants. 6 $/ \mathrm{m} /$ initial words were removed. Among the $6 / \mathrm{b} /$ initial and $8 / \mathrm{p} /$ initial words included in the original set of 20 items, we further removed two /p/ initial stimuli, one based on very short mean acoustic duration (pont, mean acoustic duration $210 \mathrm{~ms}$ ) and one based on the onset consonant cluster (plante, $\mathrm{p}+\mathrm{l}$ as there was no equivalent $\mathrm{b}+\mathrm{l}$ word among the stimuli). We therefore restricted the analysis to six words starting with /b/ (balai - broom -, botte - boot -, bougie - candle -, bouteille - bottle -, bras -arm -, bureau - desk-) and six with /p/ (peigne - comb -, piano - piano -, pinceau paintbrush -, poche - pocket -, poire - pear -, prise - plug -). The p-onset and b-onset stimuli were matched on a set of lexical and sub-lexical properties (lexical frequency, length in phonemes, phonological neighborhood, presence of word onset cluster).

In addition, for the sake of the analyses presented here we selected post-hoc a subset of trials within a given range of production latencies (RTs) and of duration of the acoustic signal, namely trials with RTs between 500 and 650 ms and with acoustic duration between 300 and 500 ms. These timeranges were selected (1) to ensure that the baseline time window for the ERP analyses (see below) fell within the same periods for all trials, notably after the end of articulation for all analysed trials and (2) to limit the variation of the pre-response encoding time-window. As baseline selection is always an issue in EEG signal analysis, we chose to use two different time-periods as baselines for time-frequency analyses (see below); this allowed a testing of the robustness of the observed effects. The choice of the range of acoustic duration of the trials $(300-500 \mathrm{~ms})$ is also related to this issue. It allows us to have baselines on a similar portion of the ERP signal across all trials, and to compare our results for pre-stimulus period and post-vocal offset baselines of the same duration.

After pre-processing (see EEG acquisition and pre-processing) and the above trial-inclusion criteria were applied, only 10 participants still had a minimum of 30 stimulus- and response- aligned epochs. We highlight that this restriction was applied before any statistical analyses had been performed.

\section{Alignment of vocal onset}

The vocal responses were manually checked for accuracy, and their onset was determined visually using the software Praat (Boersma \& Weenink, 2016) based on the onset of acoustic energy, as is typically done in language production studies (some studies have relied on automatic detections of acoustic onsets by a vocal key, but the reliability of the vocal key has been questioned many times in the literature; e.g. Kessler, Treiman, \& Mullenix, 2007). Such detected onset corresponded to 
different articulatory events for $b$ - and $p$-initial words. Labial plosives such as $p$ and $b$ are realised by successively closing the lips to stop the air from going through and by then releasing the air abruptly (burst). In French, during the closure, the vocal folds vibrate for /b/ (about $26 \mathrm{~ms}$ in Caramazza, \& Yeni-Komshian, 1974) but remain still for $/ \mathrm{p} /{ }^{1}$. In more technical terms, for $/ \mathrm{b} /$ the onset of vocal fold vibration starts before the release of the occlusion resulting in a negative Voice Onset Time (e.g., Keating, 1984), while for $/ p /$ the onset of vocal fold vibration is close to the release of the occlusion resulting in a Voice Onset Time of about 0 . Because of this difference, the onset of acoustic energy for p-initial words corresponds to the onset of the release burst. For b-initial words, the onset of acoustic energy corresponds, in most trials, to the onset of voicing. Typical examples of acoustic onsets for $\mathrm{p}$ - and $\mathrm{b}$ - initial words are presented in Figure 1.

*** Figure 1 about here $* * *$

\section{EEG pre-processing}

Epochs of $2800 \mathrm{~ms}$ were extracted, time-locked to the stimulus (stimulus-aligned) and time-locked to the vocal response onset (response-aligned) $(-1400 \mathrm{~ms} ;+1400 \mathrm{~ms})$. Each ERP epoch was visually inspected; epochs contaminated by eye blinks or other noise artefacts were rejected and excluded from averaging. Electrodes presenting artefacts were interpolated using 3-D splines interpolation (Perrin et al. 1987); there was an average of $5 \%$ of electrodes interpolated by participant ( $\max =13.3 \%)$. Only trials with both response- and stimulus-aligned epochs were retained (an average of 81 and 65 trials per condition was kept).

\section{Microstate analyses}

The aim of microstate analyses is to determine whether conditions differ in global electric fields (e.g., Michel \& Murray, 2012; Michel, Koenig, Brandeis, Gianotti, \& Wackermann, 2009). In the present study, these analyses were used to compare the EEG topographies associated with $p$ - and b-initial words. The analysis was performed in a time window spanning from $300 \mathrm{~ms}$ before the acoustic onset to $200 \mathrm{~ms}$ afterwards.

We followed a three-step procedure. First, a TCT (topographic consistency test) was run to check that a given scalp field is consistently activated by the event of interest in the time window of analysis.

\footnotetext{
${ }^{1}$ Note that the pronunciation of $/ \mathrm{p} /$ and $/ \mathrm{b} /$ in French differs from the pronunciation of the same phonemes in English. In English, the onset of the vocal fold vibration for /p/ starts after the release of the occlusion (positive Voice Onset Time) while $/ p /$ has a Voice Onset Time of about 0 in the former/in French.
} 
The topographic consistency test implemented in the Ragu software (Koenig, Stein, Grieder, \& Kottlow, 2014) was used. This test compares the global field power (GFP) of a speaker's averaged ERPs to the empirical distribution of the GFP obtained after shuffling the data randomly across electrodes. Periods of inconsistency should therefore be discarded for subsequent analyses. The second step in the analysis consisted in a topographic analysis of variance (TANOVA; Murray, Brunet, \& Michel, 2008) to determine to what extent the topography (as indexed by the global dissimilarity index, Lehmann \& Skrandies, 1980) of the ERPs differs across conditions. The procedure based on permutation tests and implemented in the Ragu software was used (see Koenig, Stein, Grieder, \& Kottlow, 2014, for details). The data were normalized prior to the analysis, 5000 iterations were used and the significance threshold was set to 0.01 . The third step consists in a topographic pattern analysis. This analysis allows determining whether differences across conditions arise because the sets of periods of stable electrophysiological activity (topographic maps) differ across conditions, or because of differences in the time course of the topographic maps. In the present study, the method described by Koenig et al. (2014) was used to perform the topographic pattern analysis.

\section{Time-frequency analyses}

Time-frequency decompositions of the EEG signal were obtained using Hanning convolutions of 6 cycles that were computed from 1 to $50 \mathrm{~Hz}$ in steps of $1 \mathrm{~Hz}$ on sliding windows of $50 \mathrm{~ms}$ over i) the $500 \mathrm{~ms}$ period around vocal response onset $(-300+200 \mathrm{~ms})$ and ii) the two $500 \mathrm{~ms}$ periods chosen as baselines: prior to picture onset $(-700-200 \mathrm{~ms})$ and post vocal offset $(+700+1200 \mathrm{~ms})$ (see supplementary material2). Time-frequency representations were averaged over trials for each participant and condition (i.e. onset phoneme).

Statistical analyses were carried out on oscillatory power by means of a cluster-based nonparametric analysis (Maris \& Oostenveld, 2007) on separate averaged frequency bands (Alpha 8-14 $\mathrm{Hz}$, Beta $15-29 \mathrm{~Hz}$ and Gamma 30-50 Hz). This approach allows to compare the signal power between conditions over channels and time-windows while avoiding the problem of multiple comparisons. Spatial adjacency was set to three neighboring channels. Only clusters over a given significance level were kept. This was determined by building a distribution stemming from the data itself by successive random permutations (Monte Carlo; 2000 randomizations) of the two experimental conditions being compared. Alpha-level was set at .05 . The procedure was conducted to compare signal around vocal response onset to the baseline periods for each phoneme separately.

\section{Results}

Microstates analyses 
The topographic consistency test revealed that the ERPs were consistent for both conditions in the time window of interest (300 ms prior to vocal onset to $200 \mathrm{~ms}$ afterwards). This allowed us to perform the TANOVA and the microstate analysis on the entire time-window. The TANOVA analysis revealed significant differences between the two conditions throughout the time window: notably from about 125 to $45 \mathrm{~ms}$ before the onset of articulation, and from about 45 to 135 after the onset of articulation. The topographic pattern analysis revealed no significant differences in the set of topographic maps for the two conditions but differences in the onset and offset of three consecutive maps. The first of these maps started around $150 \mathrm{~ms}$ and $110 \mathrm{~ms}$ before the onset of articulation for $/ \mathrm{p} /$ and $/ \mathrm{b} /$ respectively $(p=0.0042)$ and ended around $130 \mathrm{~ms}$ before the onset of articulation for $/ \mathrm{p} /$ and $95 \mathrm{~ms}$ for $/ \mathrm{b} /(p=0.0088)$ (see Figure2). The second of these maps ended around $120 \mathrm{~ms}$ before the onset of articulation for $/ \mathrm{p} /$ and $75 \mathrm{~ms}$ for $/ \mathrm{b} /(p=0.0042)$. The last map ended around $100 \mathrm{~ms}$ before the onset of articulation for $/ \mathrm{p} /$ and around $55 \mathrm{~ms}$ for $/ \mathrm{b} /(p=0.0042)$. The average difference in onset/offset between $\mathrm{p}$ initial and $\mathrm{b}$ initial words is $40 \mathrm{~ms}$.

\section{*** Figure 2 about here $* * *$}

\section{Time-frequency analyses}

Figures $3 a$ and $3 b$ (left panel) depict time-frequency decompositions around vocal onset for trials involving the onset phonemes $/ \mathrm{b} /$ and $/ \mathrm{p} /$, respectively. Power spectra indicated enhanced power in the gamma band $(30-50 \mathrm{~Hz})$ around articulation relative to pre-picture onset baseline for both phonemes. There were two temporally disjoint significant clusters of activity over peripheral electrodes for the phoneme /b/ (in red on Figure 3a, middle panel), from -100 to $-50 \mathrm{~ms}$ prior to vocal onset $(p<0.001)$ and from 50 to $200 \mathrm{~ms}$ post vocal onset $(p=0.007)$. One significant cluster was observed for the phoneme / $\mathrm{p}$ / (in red on Figure 3b middle panel), from -150 prior to vocal onset $(p<0.001)$. The number of electrodes showing this pattern increased with proximity to the vocal onset (see Figure 3a, middle panel).

Enhanced power was also found in the beta band (15-29 Hz), on peripheral electrodes, from vocal onset to $200 \mathrm{~ms}$ afterwards (one significant cluster for $/ \mathrm{b} /, p=0.01$, and $/ \mathrm{p} /, \mathrm{p}=0.0245$ ) (see Figure 3, right panel). Moreover, significantly reduced power in the beta band was observed prior to vocal onset. For the phoneme /b/, a significant cluster ( $p=0.0175$, in blue on Figure 3a, right panel) of about fifteen central electrodes showed this pattern from 300 to 100 ms prior to vocal onset. For /p/, significant reduced power was observed up to $150 \mathrm{~ms}$ prior to vocal onset $(p=0.017$, in blue on Figure $3 b$, right panel). 
While no effect was found in the alpha band $(8-14 \mathrm{~Hz})$ for /b/ trials, one cluster lasting $50 \mathrm{~ms}$ (around $150 \mathrm{~ms}$ prior to vocal onset) showed reduced power for the phoneme /p/ trials, yet it was restricted to 4 electrodes on centro-posterior sites ( $p=0.034$; not shown).

In sum, the same pattern of increased power in the gamma and beta bands (with a similar spatial distribution) was observed for both phonemes but with a trend for an earlier onset for $/ \mathrm{p} / \mathrm{trials}$. The decreased power in the beta band had a different spatial distribution than the increased beta power (central vs. peripheral sites) but was similar across phoneme onsets. Comparable results were obtained when the baseline was taken post-vocal offset (see supplementary material2).

*** Figure 3 about here $* * *$

\section{General Discussion}

The first aim of this research was to show how the properties of the first phoneme influence the alignment of ERPs to the vocal response, and therefore the response-aligned signal. The comparison of ERPs aligned to the onset of the vocal responses, defined with the usual criterion (onset of acoustic energy) for words starting with /p/ versus /b/, revealed a delay in the set of stable electrophysiological patterns (topographic maps) for the two word lists. An important and significant shift in the time course of these maps was observed. There was no evidence that the two conditions differed in the sets of topographic patterns. This result is as expected given that $/ \mathrm{p} /$ and $/ \mathrm{b} /$, despite involving the same articulatory movements, differ in terms of the time interval between the onset of the articulatory movement and the onset of the acoustic energy. Yet, this $40 \mathrm{~ms}$ shift is remarkably consistent with the length of the voiced proportion of the acoustic signal prior to the release of the closure in the vocal responses we recorded. This value is in the range of values usually reported for such pre-voicing (e.g., 26 ms in Caramazza \& Yeni-Komshian, 1974, around 130 for young adults in Ryalls, Cliche, Fortier-blanc, Coulombe, \& Prud'hommeaux (1997)). A shift of similar duration was also observed for the power increase of oscillations in the gamma band, which had an earlier onset for $/ \mathrm{p} /$ trials ( $150 \mathrm{~ms}$ before vocal onset) than for $/ \mathrm{b} /$ trials (about $100 \mathrm{~ms}$ before vocal onset). While these findings are not surprising, the clear-cut shifts in time of the EEG activity have important methodological consequences for the analysis of response-aligned ERPs in speech and language production experiments. They show that if conditions are not balanced in initial phonemes, differences in the acoustic properties of the stimuli may generate spurious effects in the ERPs, i.e. effects that have nothing to do with the manipulation of interest. From a more general perspective, 
the onset of the acoustic energy in the vocal responses does not seem an optimal trigger for synchronizing the EEG activity to the response. The onset of the underlying muscular activity would provide a more representative trigger, at the expense of considerably more complex recordings (placing multiple electrodes on the face articulators; van der Linden et al., 2014).

The second aim of this study was to further characterize the EEG signal around the onset of articulation. In the following we discuss how the frequency range, pattern of modulations and scalp distribution of oscillatory changes converge to indicate that gamma and beta power increases reflect (motor) activity resulting from articulation-related artefacts whereas beta suppression results from pre-articulatory cortical processes.

The beta oscillations recorded in the present experiment were most likely generated by the primary motor cortex M1 and their desynchronization over central sites corresponds to increased cortical motor activity (Pfurtscheller \& Lopes da Silva, 1999). Interestingly, in our data, the power decrease in the beta band precedes the onset of the verbal response and is not sustained after it, which might relate the effect to the retrieval of speech motor plans (phonetic encoding) rather than to articulation itself (see Flinker et al., 2015, for a similar contrast). Speech motor control is complex in the sense that it entails not only the overt production of the utterance but the combination of synchronized breathing, mouth opening, and movements of lips, tongue and vocal cords. Some studies have reported cortical motor preparatory potentials related to pre-phonatory breath and mouth opening movements over central electrodes (Tremoureux et al., 2014; Yoshida et al., 1999). Our results complement this literature by showing that beta band power decrease is associated with speech motor preparation and that its timing seems sensitive to phonetic characteristics (here the voicing feature) of the first phoneme of an utterance.

In contrast, power increases rather seem to start with response onset. Power increases in gamma and beta bands show the same scalp distribution, and the timing of the beta power increase follows gamma ones. Both these effects could reflect articulation-related activity (Muthukumaraswamy, 2013; see Ouyang et al., 2016 , for discussion of artifacts originating in high frequencies). As power increase in the gamma band has been linked to EMG activity (Pope et al, 2009), these processes might correspond to articulation-related activity, which would have different onsets as a function of the initial phoneme of the word to be uttered. Gamma oscillations around $40 \mathrm{~Hz}$ seem particularly sensitive to tongue movements (see Pfurtscheller, Neuper, \& Kalcher, 1993), for which oscillatory modulations have been observed over the central-posterior part of the scalp. Given that the period of articulation requires strong muscular activity from a variety of effectors, it seems likely that the beta and gamma increases indeed correspond to articulation-related activity. 
An alternative hypothesis, which we believe to be less likely, is that beta power increase also reflects monitoring processes during speech planning. Beta power increase has been reported in a Stroop task (Piai et al, 2012) and monitoring-related activity could originate from supplementary motor area (Möller et al. 2007; see also Riès et al, 2011), which would likely elicit a similar topography of beta power. The reported beta power increase could reflect both articulation- and monitoring- related activity originating from medial frontal regions, if it were not for the relationship between gamma and beta power increases. The reliable association observed between these frequency bands strongly suggests related mechanisms, while the role of gamma band power in monitoring hasn't been formally established so far, therefore arguing for the articulation-related interpretation.

Note that the increases in gamma and beta bands power were detected at earliest around $150 \mathrm{~ms}$ before vocal onset for the voiceless phoneme /p/ and around $100 \mathrm{~ms}$ for the voiced phoneme /b/. These observations are at variance with previous studies which found different (i.e. earlier) time distribution of the artefact (see Ouyang et al., 2016; Porcaro et al., 2014). Such differences could be largely due to methodological decisions (see Van der Linden et al., 2014). For instance, Porcaro and collaborators (2014) reported speech motor artefacts as early as 400 ms post stimulus onset, as well as earlier traces of artefactual activity around $160 \mathrm{~ms}$ post stimulus onset. However, these observations likely resulted from having averaged trials with response times ranging from 250 to $1800 \mathrm{~ms}$. This means that there was a substantial proportion of trials in which articulation was already engaged around $400 \mathrm{~ms}$ post stimulus onset. In this case, restricting analyses to stimulusaligned epochs can be particularly misleading. In contrast, here we overcame this caveat first by restricting the analysis to trials with similar response latencies and second by presenting results aligned to the verbal response. By doing so, articulation-related activity is found only from $150 \mathrm{~ms}$ pre-verbal response onwards.

Another important methodological feature is that studies aiming at either describing or removing the artefacts do not use the same pre-processing procedures. Ouyang et al. (2016) explored EEG signals with a low-pass filter of $70 \mathrm{~Hz}$ (i.e. frequency band of gamma oscillations) to cover the range of electromyographic activity, whereas most language production research uses low-pass filters of 30 $\mathrm{Hz}$. In that latter case, there seems to be no sign of articulation-related activity before verbal onset, although heavy filtering is not an efficient way of eliminating the EMG related activity during articulation (Porcaro et al., 2014). The present study aimed at enlarging this perspective by describing time-frequency patterns over the articulatory period. In particular, the beta power (15-29 $\mathrm{Hz}$ ) increase suggests that traces of artefactual muscular activity might be present in the EEG signal even if a low-pass filter was applied at $30 \mathrm{~Hz}$. 
The analyses reported in the present study contribute to further characterize the EEG signal around the onset of articulation. Analyzing the time-course of topographic stability and of the oscillatory dynamics provided clear cues to link the EEG signal to the muscle artefact that precedes and accompanies overt articulation. Moreover, our results demonstrate that phonetic features of the word onset phoneme constitute an important parameter affecting response-locked ERPs recorded during speech production tasks.

Finally, it should be noted that although different methods are available for reducing EMG artefacts (regression, CCA, ICA decomposition, etc. Pham et al., 2011; Vigario \& Oja, 2008; see Urigüen and Garcia-Zapirain, 2015 for a review), none can guarantee that the analyzed data are free of highfrequencies originating artefacts (Muthukumaraswamy, 2013). As argued by De Vos et al. (2010), for instance, the sensitivity of ICA to the diversity of words in a dataset could yield an excessive number of sources and thus result in an inefficient removal of artefactual components. Yet, in light of the results reported here, future work could investigate the efficiency of correction methods such as ICA by incorporating spectral decompositions.

Based on the quantitative indexes explored in this methodological report, we submit that future work should be devoted to delineating the influence of artefacts in the signal rather than only attempting to remove them "blindly", in order to draw conclusions about germane cognitive processes. 


\section{References}

Alario, F. X., \& Ferrand, L. (1999). A set of 400 pictures standardized for French: norms for name agreement, image agreement, familiarity, visual complexity, image variability, and age of acquisition. Behavior Research Methods, Instruments, \& Computers: A Journal of the Psychonomic Society, Inc, 31(3), 531-552.

Blackford, T., Holcomb, P. J., Grainger, J., \& Kuperberg, G. R. (2012). A funny thing happened on the way to articulation: N400 attenuation despite behavioral interference in picture naming. Cognition, 123(1), 84-99. https://doi.org/10.1016/j.cognition.2011.12.007

Boersma, P., \& Weenink, D. (2016). Praat: doing phonetics by computer [Computer program]. Version 6.0.23. Retrieved from http://www.praat.org

Bürki, A., Cheneval, P. P., \& Laganaro, M. (2015). Do speakers have access to a mental syllabary? ERP comparison of high frequency and novel syllable production. Brain and Language, 150, 90-102. https://doi.org/10.1016/j.bandl.2015.08.006

Bürki, A., Sadat, J., Dubarry, A.-S., \& Alario, F.-X. (2016). Sequential processing during noun phrase production. Cognition, 146, 90-99. https://doi.org/10.1016/j.cognition.2015.09.002

Caramazza, A. \& Yeni-Komshian, G. H. (1974). Voice onset time in two French dialects. Journal of Phonetics, 2, 239-245.

Deecke, L., Engel, M., Lang, W., \& Kornhuber, H. H. (1986). Bereitschaftspotential preceding speech after holding breath. Experimental Brain Research, 65(1), 219-223.

Dell'acqua, R., Sessa, P., Peressotti, F., Mulatti, C., Navarrete, E., \& Grainger, J. (2010). ERP Evidence for Ultra-Fast Semantic Processing in the Picture-Word Interference Paradigm. Frontiers in Psychology, 1, 177. https://doi.org/10.3389/fpsyg.2010.00177

De Vos, M., Riès, S., Vanderperren, K., Vanrumste, B., Alario, F.-X., ... Burle, B. (2010). Removal of muscle artifacts from EEG recordings of spoken language production. Neuroinformatics, 8(2), 135150. https://doi.org/10.1007/s12021-010-9071-0 
Dubarry, A.-S., Llorens, A., Trébuchon, A., Carron., R., Liégeois-Chauvel, C., Bénar, C., \& Alario, F.-X., (in press). Estimating Parallel Processing in a Language Task Using Single-Trial Intracerebral Electroencephalography. Psychological Science.

Fargier, R., \& Laganaro, M. (2016). Spatio-temporal Dynamics of Referential and Inferential Naming: Different Brain and Cognitive Operations to Lexical Selection. Brain Topography. https://doi.org/10.1007/s10548-016-0504-4

Ganushchak, L. Y., Christoffels, I. K., \& Schiller, N. O. (2011). The Use of Electroencephalography in Language Production Research: A Review. Frontiers in Psychology, 2. https://doi.org/10.3389/fpsyg.2011.00208

Ganushchak, L. Y., \& Schiller, N. O. (2008). Brain error-monitoring activity is affected by semantic relatedness: an event-related brain potentials study. Journal of Cognitive Neuroscience, 20(5), 927940. https://doi.org/10.1162/jocn.2008.20514

Goncharova, I. I., McFarland, D. J., Vaughan, T. M., \& Wolpaw, J. R. (2003). Emg contamination of eeg: Spectral and topographical characteristics. Clinical Neurophysiology, 114(9), 1580-1593

Indefrey, P. (2011). The spatial and temporal signatures of word production components: a critical update. Language Sciences, 2, 255. https://doi.org/10.3389/fpsyg.2011.00255

Indefrey, P., \& Levelt, W. J. M. (2004). The spatial and temporal signatures of word production components. Cognition, 92(1-2), 101-144. https://doi.org/10.1016/j.cognition.2002.06.001

James, C. J., \& Hesse, C. W. (2005). Independent component analysis for biomedical signals. Physiological Measurement, 26(1), R15-39.

Flinker, A., Korzeniewska, A., Shestyuk, A. Y., Franaszczuk, P. J., Dronkers, N. F., Knight, R. T., \& Crone, N. E. (2015). Redefining the role of Broca's area in speech. Proceedings of the National Academy of Sciences of the United States of America, 112(9), 2871-2875. https://doi.org/10.1073/pnas.1414491112 
Jung, T. P., Makeig, S., Westerfield, M., Townsend, J., Courchesne, E., \& Sejnowski, T. J. (1999). Analyzing and visualizing single-trial event-related potentials. Advances in Neural Information Processing Systems 11, 11, 118-124\r1090.)

Keating, P. A. (1984). Phonetic and Phonological Representation of Stop consonant Voicing. Language, 60(2): 286-319.

Kessler, B., Treiman, R., \& Mullenix, J. (2007). Feedback-consistency effects in single-word reading. In E. L. Grigorenko \& A. J. Naples, Single-word reasing: Behavioral and biological perspectives (NJ: Lawrence Erlbaum Associates, Inc, pp. 159-174). Hillsdale.

Koenig, T., Stein, M., Grieder, M., \& Kottlow, M. (2014). A tutorial on data-driven methods for statistically assessing ERP topographies. Brain Topography, 27(1), 72-83. https://doi.org/10.1007/s10548-013-0310-1

Laganaro, M. (2014). ERP topographic analyses from concept to articulation in word production studies. Frontiers in Psychology, 5, 493. https://doi.org/10.3389/fpsyg.2014.00493

Laganaro, M., \& Perret, C. (2011). Comparing electrophysiological correlates of word production in immediate and delayed naming through the analysis of word age of acquisition effects. Brain Topography, 24(1), 19-29. https://doi.org/10.1007/s10548-010-0162-x

Lehmann, D., \& Skrandies, W. (1980). Reference-free identification of components of checkerboardevoked multichannel potential fields. Electroencephalography and Clinical Neurophysiology, 48(6), 609-621. https://doi.org/10.1016/0013-4694(80)90419-8

Levelt, W. J., Roelofs, A., \& Meyer, A. S. (1999). A theory of lexical access in speech production. The Behavioral and Brain Sciences, 22(1), 1-38; discussion 38-75.

Llorens, A., Trébuchon, A., Riès, S., Liégeois-Chauvel, C., \& Alario, F.-X. (2014). How familiarization and repetition modulate the picture naming network. Brain and Language, 133, 47-58. https://doi.org/10.1016/j.bandl.2014.03.010

Maris, E., \& Oostenveld, R. (2007). Nonparametric statistical testing of EEG- and MEG-data. Journal of Neuroscience Methods, 164(1), 177-190. https://doi.org/10.1016/j.jneumeth.2007.03.024 
Masaki, H., Tanaka, H., Takasawa, N., \& Yamazaki, K. (2001). Error-related brain potentials elicited by vocal errors. Neuroreport, 12(9), 1851-1855.

Michel, C. M., Koenig, T., Brandeis, D., Gianotti, L. R., \& Wackermann, J. (2009). Electrical Neuroimaging. Cambridge, MA: Cambridge University Press.

Michel, C. M., \& Murray, M. M. (2012). Towards the utilization of EEG as a brain imaging tool. Neurolmage, 61(2), 371-385. https://doi.org/10.1016/j.neuroimage.2011.12.039

Möller, J., Jansma, B.M., Rodriguez-Fornells, A., Münte, T.F. (2007). What the Brain Does before the Tongue Slips. Cereb Cortex 2007; 17 (5): 1173-1178. doi: 10.1093/cercor/bhl028

Munding, D., Dubarry, A.-S., \& Alario, F.-X. (2015). On the cortical dynamics of word production: a review of the MEG evidence. Language, Cognition and Neuroscience, $0(0), 1-22$. https://doi.org/10.1080/23273798.2015.1071857

Murray, M. M., Brunet, D., \& Michel, C. M. (2008). Topographic ERP analyses: a step-by-step tutorial review. Brain Topography, 20(4), 249-264. https://doi.org/10.1007/s10548-008-0054-5

Muthukumaraswamy, S. D. (2013). High-frequency brain activity and muscle artifacts in MEG/EEG: a review and recommendations. Frontiers in Human Neuroscience, 7, 138. https://doi.org/10.3389/fnhum.2013.00138

Ouyang, G., Sommer, W., Zhou, C., Aristei, S., Pinkpank, T., \& Abdel Rahman, R. (2016). Articulation Artifacts During Overt Language Production in Event-Related Brain Potentials: Description and Correction. Brain Topography, 29(6), 791-813. https://doi.org/10.1007/s10548-016-0515-1

Piai, V., Roelofs, A. \& van der Meij, R. (2012). Event-related potentials and oscillatory brain responses associated with semantic and Stroop-like interference effects in overt naming. Brain Research. 23(1450):87-101.

Pfurtscheller, G., \& Lopes da Silva, F. H. (1999). Event-related EEG/MEG synchronization and desynchronization: basic principles. Clinical Neurophysiology: Official Journal of the International Federation of Clinical Neurophysiology, 110(11), 1842-1857. 
Pfurtscheller, G., Neuper, C., \& Kalcher, J. (1993). 40-Hz oscillations during motor behavior in man. Neuroscience Letters, 164(1-2), 179-182.

Pham, A. V., Fine, J. G., \& Semrud-Clikeman, M. (2011). The influence of inattention and rapid automatized naming on reading performance. Archives of Clinical Neuropsychology: The Official Journal of the National Academy of Neuropsychologists, 26(3), 214-224. https://doi.org/10.1093/arclin/acr014

Porcaro, C., Medaglia, M. T., \& Krott, A. (2015). Removing speech artifacts from electroencephalographic recordings during overt picture naming. Neurolmage, 105, 171-180. https://doi.org/10.1016/j.neuroimage.2014.10.049

Rastle, K., Croot, K. P., Harrington, J. M., \& Coltheart, M. (2005). Characterizing the motor execution stage of speech production: consonantal effects on delayed naming latency and onset duration. Journal of Experimental Psychology. Human Perception and Performance, 31(5), 1083-1095. https://doi.org/10.1037/0096-1523.31.5.1083

Riès, S., Janssen, N., Burle, B., \& Alario, F.-X. (2013). Response-locked brain dynamics of word production. PloS One, 8(3), e58197. https://doi.org/10.1371/journal.pone.0058197

Ryalls, J., Cliche, A., Fortier-blanc, J., Coulombe, I., \& Prud'hommeaux, A. (1997). Voice-onset time in younger and older French-speaking Canadians. Clinical Linguistics \& Phonetics, 11 (3), 205-212. http://dx.doi.org/10.3109/02699209708985191

Schmitt, B.M., Münte, T.F. \& Kutas, M. (2000). Electrophysiological estimates of the time course of semantic and phonological encoding during implicit picture naming. Psychophysiology, 37 (4), 473484

Strijkers, K., Costa, A., \& Thierry, G. (2010). Tracking lexical access in speech production: electrophysiological correlates of word frequency and cognate effects. Cerebral Cortex (New York, N.Y.: 1991), 20(4), 912-928. https://doi.org/10.1093/cercor/bhp153

Tremoureux, L., Raux, M., Ranohavimparany, A., Morélot-Panzini, C., Pouget, P., \& Similowski, T. (2014). Electroencephalographic evidence for a respiratory-related cortical activity specific of the 
preparation of prephonatory breaths. Respiratory Physiology \& Neurobiology, 204, 64-70. https://doi.org/10.1016/j.resp.2014.06.018

Urigüen, J. A., \& Garcia-Zapirain, B. (2015). EEG artifact removal-state-of-the-art and guidelines. Journal of Neural Engineering, 12(3), 031001. https://doi.org/10.1088/1741-2560/12/3/031001

van der Linden, L., Riès, S. K., Legou, T., Burle, B., Malfait, N., \& Alario, F.-X. (2014). A comparison of two procedures for verbal response time fractionation. Frontiers in Psychology, 5, 1213. https://doi.org/10.3389/fpsyg.2014.01213

van Turennout, M., Hagoort, P., \& Brown, C. (1999). The time course of grammatical and phonological processing during speaking: evidence from event-related brain potentials. Journal of Psycholinguistic Research, 28(6), 649-676.

Vigario, R., \& Oja, E. (2008). BSS and ICA in neuroinformatics: from current practices to open challenges. IEEE Reviews in Biomedical Engineering, 1, 50-61. https://doi.org/10.1109/RBME.2008.2008244

Whitham, E. M., Pope, K. J., Fitzgibbon, S. P., Lewis, T., Clark, C. R., Loveless, S., ... Willoughby, J. O. (2007). Scalp electrical recording during paralysis: quantitative evidence that EEG frequencies above $20 \mathrm{~Hz}$ are contaminated by EMG. Clinical Neurophysiology: Official Journal of the International $\begin{array}{llll}\text { Federation } \quad \text { of } & \text { Clinical 1877-1888. }\end{array}$ https://doi.org/10.1016/j.clinph.2007.04.027

Yoshida, K., Kaji, R., Hamano, T., Kohara, N., Kimura, J., \& lizuka, T. (1999). Cortical distribution of Bereitschaftspotential and negative slope potential preceding mouth-opening movements in humans. Archives of Oral Biology, 44(2), 183-190. 


\begin{abstract}
Author notes
This work was partly supported by a French-Swiss grant "Germaine de Staël" (N²013-22) from the "Partenariat Hubert Curien" program.
\end{abstract}

1

2

3

4

5

6

10

11

12

13

14

15

16

17

18

19

20

21

22

23

24

25

26

27

28

29

30

31

32

33

34

35

36

37

38

39

40

41

42

43

44

45

46

47

48

49

50

51

52

53

54

55

56

57

58

59

60 


\section{Figure captions}

Figure 1: Time course of acoustic energy for $p$-intial word (left) and b-intial words (right), with respective phoneme onsets marked.

Figure 2: Grand-average ERPs for /b/ and /p/ words with an oscillogram of the vocal responses and their onsets as well as results of the topographic analysis. Electrophysiological configurations at scalp of microstates are presented and distinguished by color. Colored-shaded areas correspondingly indicate duration of each microstate. As evidenced in the upper panel, differences in amplitudes are observed but no clear ERP components emerge in the response-aligned epoch.

Figure 3: Time-frequency decompositions (left panel) of grand-average ERPs and corresponding statistical analyses (middle and right panel) for /b/ words (a) and /p/ words, computed against a prestimulus baseline (b). Outputs of the cluster-based permutation analyses for each condition in the Gamma band (middle panel) and in the Beta band (right panel) are given. Each bar represents statistically significant 50 ms time-bin on a single electrode. Spatial distribution of the electrodes showing the effect is indicated on the central row.

Supplementary material.

Supplementary material1. Time-frequency decompositions of grand-average ERPs in the period corresponding to the pre-stimulus onset period for the phoneme /b/ (a) and the phoneme /p/ (b).

Supplementary material2. Statistical analyses (middle and right panel) for the /b/ words (a) and the /p/ words (b), computed against a post-vocal offset baseline. Outputs of the cluster-based permutation analyses for each phoneme in the Gamma band (middle panel) and in the Beta band (right panel) are given. Each bar represents statistically significant $50 \mathrm{~ms}$ time-bin on single electrodes. Spatial distribution of the electrodes showing the effect is indicated on the central row. 

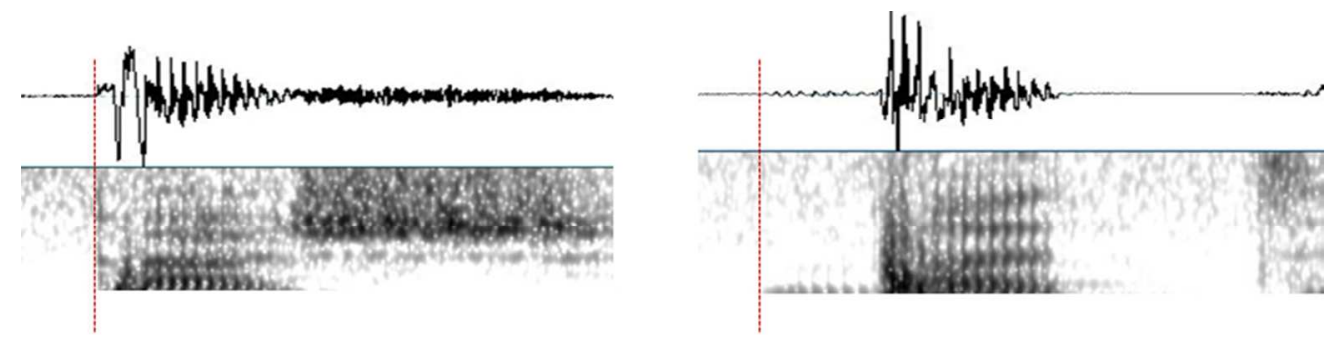

Figure 1: Onset of acoustic energy for $p$-intial word (left) and b-intial words (right).

$$
69 \times 17 \mathrm{~mm}(300 \times 300 \text { DPI })
$$




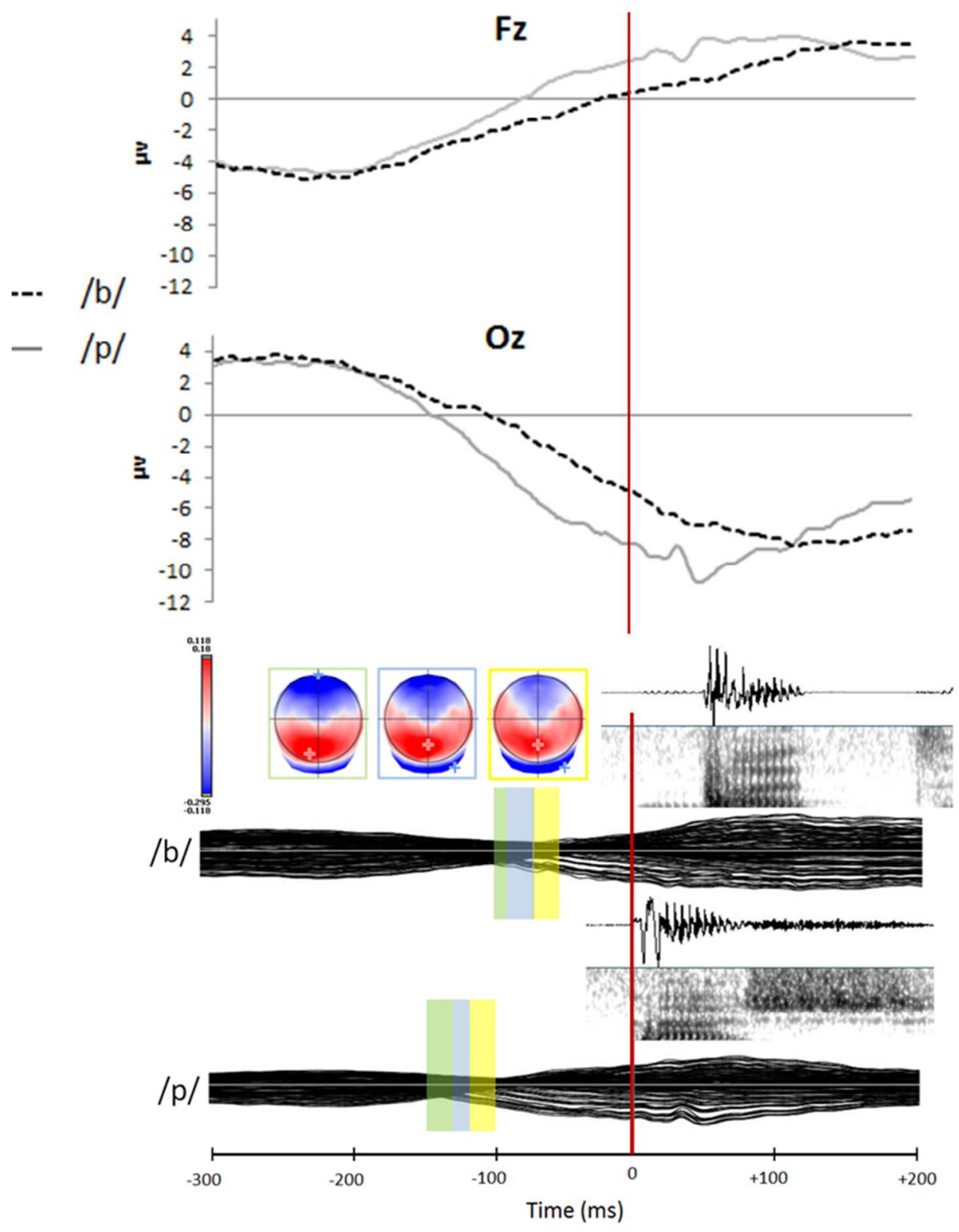

Figure 2: Grand-average ERPs for $b$ and $\mathrm{p}$ with spectrogram/oscillogram of the vocal responses and their onsets as well as results of the topographic analysis. As evidenced in the upper panel, differences in amplitudes are observed but no clear ERP components emerge in the response-aligned epoch.

\section{$62 \times 81 \mathrm{~mm}(300 \times 300$ DPI $)$}


Figure 3: Time-frequency decompositions (left panel) of grand-average ERPs and corresponding statistical analyses (middle and right panel) for the phoneme /b/ (a) and the phoneme / $\mathrm{p} /(\mathrm{b})$. Outputs of the clusterbased permutation analyses for each phoneme in the Gamma band (middle panel) and in the Beta band (right panel) are given. Spatial distribution of the electrodes showing the effect is indicated on the central row.

$169 \times 95 \mathrm{~mm}(300 \times 300 \mathrm{DPI})$ 


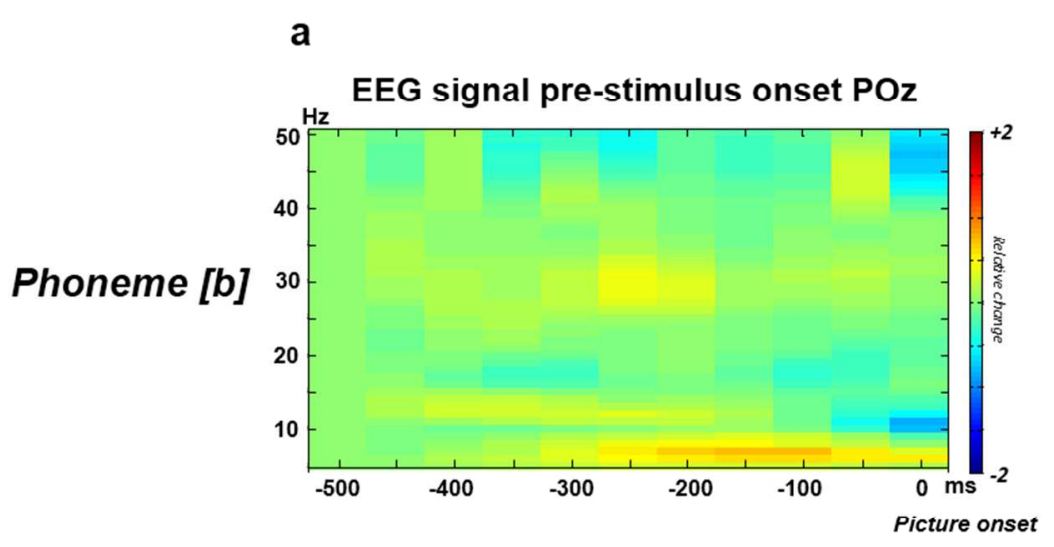

b

Phoneme [p]

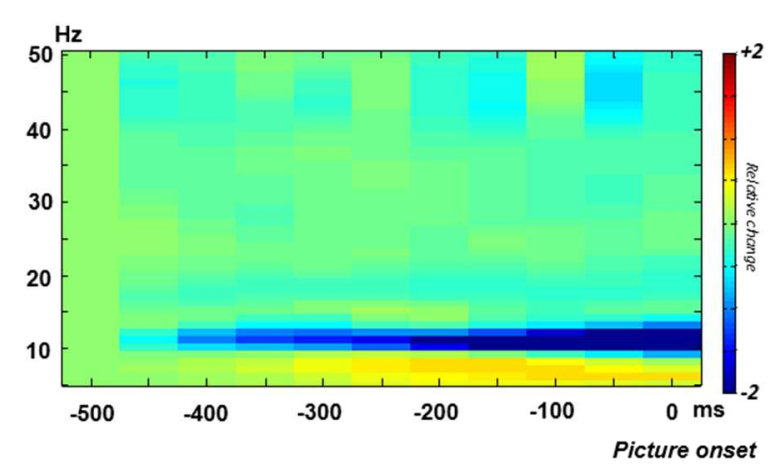

$163 \times 157 \mathrm{~mm}(150 \times 150 \mathrm{DPI})$ 


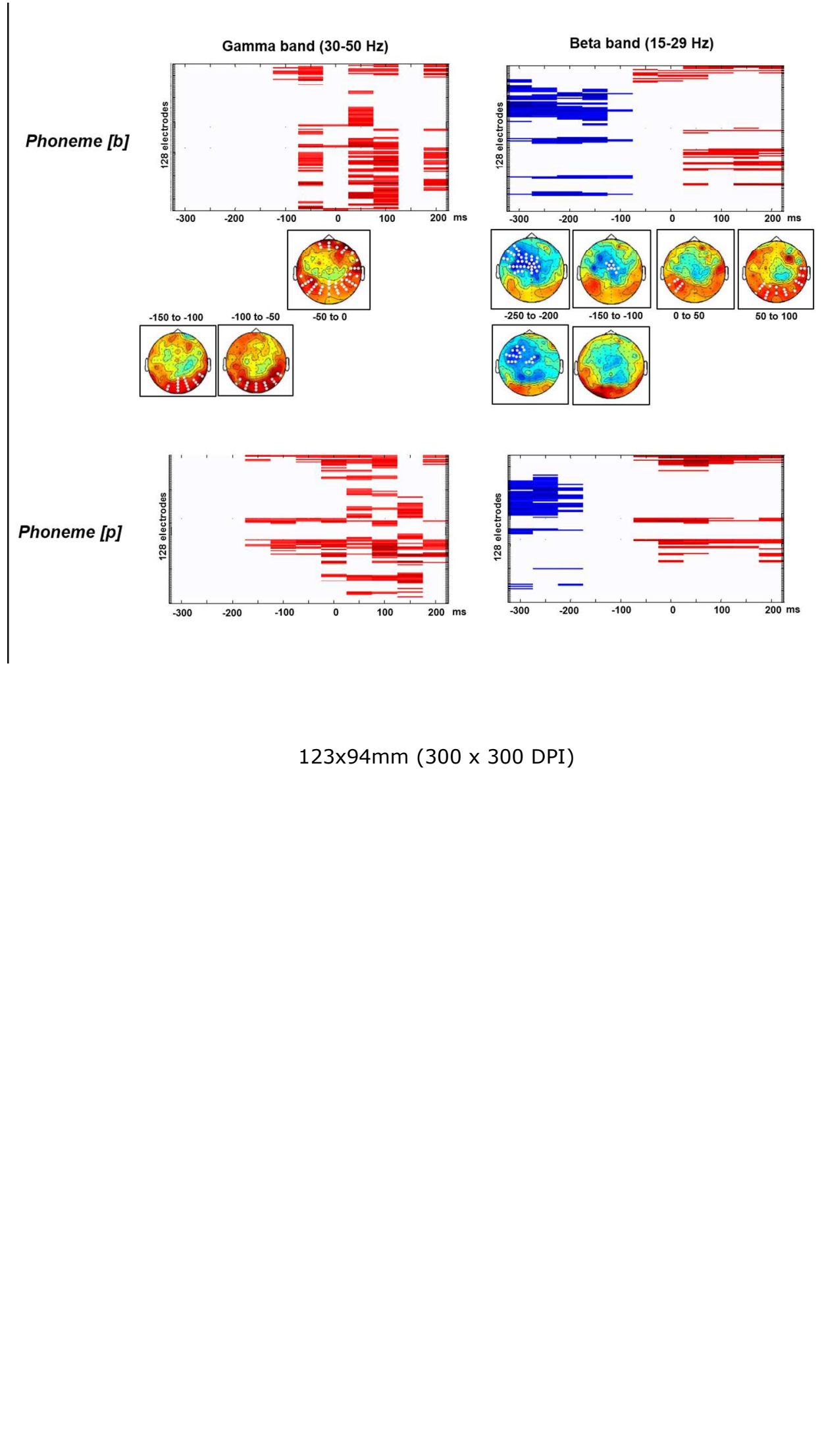

